\title{
ANALYTIC SMOOTHING EFFECT FOR A SYSTEM OF NONLINEAR SCHRÖDINGER EQUATIONS
}

\author{
GAKU HOSHINO AND TOHRU OZAWA
}

Abstract. We prove the global existence of analytic solutions to the Cauchy problem for a system of nonlinear Schrödinger equations with quadratic interaction in space dimension $n \geqslant 3$ under the mass resonance condition. Lagrangian formulation is also described.

Mathematics subject classification (2010): 35Q55.

Keywords and phrases: nonlinear Schrödinger equation, analyticity.

\section{REFERENCES}

[1] J.-L. Bona, Z. GRUjIĆ AND H. KALISCH, Global solutions of the derivative Schrödinger equation in a class of functions analytic in a strip, J. Differential Equations, 229 (2006), 186-203, doi:10.1016/j.jde.2006.04.013.

[2] T. Cazenave, Semilinear Schrödinger equations, Courant Lecture Notes in Math., 10 Amer. Math. Soc., 2003.

[3] T. Cazenave, And F.B. Weissler, The Cauchy problem for the critical nonlinear Schrödinger equation in $H^{s}$, Nonlinear Analysis, TMA., 14 (1990), 807-836, doi:10.1016/0362-546X(90)90023A.

[4] A. Debouard, Analytic solution to nonelliptic nonlinear Schrödinger equations, J. Differential Equations, 104 (1993), 196-213, doi:10.1006/jdeq.1993.1069.

[5] J. Ginibre, Introduction aux équations de Schrödinger non linéaires, Paris Onze Edition, L161. Université Paris-Sud, 1998.

[6] N. HAYASHI, Global existence of small analytic solutions to nonlinear Schrödinger equations, Duke Math. J., 60 (1990), 717-727, doi:10.1215/S0012-7094-90-06029-6.

[7] N. HaYASHI AND K. KATO, Analyticity in time and smoothing effect of solutions to nonlinear Schrödinger equations, Commun. Math Phys., 184 (1997), 273-300, doi:10.1007/s002200050061.

[8] N. Hayashi, C. Li And T. Ozawa, Small data scattering for a system of nonlinear Schrödinger equations, Differ. Equ. Appl., 3 (2011), 415-426.

[9] N. Hayashi And T. OZAWA, On the derivative nonlinear Schrödinger equation, Physica D, 55 (1992), 14-36, doi:10.1016/0167-2789(92)90185-P.

[10] N. HAYAShi, T. OZAWA AND K. TANAKA, On a system of nonlinear Schrödinger equations with quadratic interaction, Ann. Inst. H. Poincaré Anal. Non Linéaire, 30, (2013), 661-690, doi:10.1016/j.anihpc.2012.10.007

[11] N. HaYASHI AND S. SAITOH, Analyticity and smoothing effect for the Schrödinger equation, Ann. Inst. Henri Poincaré, Phys. Théor., 52 (1990), 163-173.

[12] N. HAYASHI AND S. SAITOH, Analyticity and global existence of small solutions to some nonlinear Schrödinger equations, Commun. Math. Phys., 129,(1990) 27-41, doi:10.1007/BF02096777.

[13] G. Hos HINO AND T. OZAWA, Analyticity smoothing effect for nonlinear Schrödinger equation in two space dimensions, Osaka J. Math, (in press).

[14] K. KATO AND K. TANIGUCHI, Gevrey regularizing effect for nonlinear Schrödinger equations, Osaka. J. Math., 33 (1996), 863-880.

[15] T. KATO, On nonlinear Schrödinger equations.II $H^{s}$-solutions and unconditional well-posedness, J. d'Anal. Math., 67 (1995), 281-306. 
[16] T. Kato And K. Masuda, Nonlinear evolution equations and analyticity, Ann. Inst. Henri Poincaré, Analyse non linéaire, 3 (1986), 455-467.

[17] K. NaKAmitsu, Analytic finite energy solutions of the nonlinear Schrödinger equation, Commun. Math. Phys., 260 (2005), 117-130, doi:10.1007/s00220-005-1405-7.

[18] M. NAKAMURA AND T. OZAWA, Low energy scattering for nonlinear Schrödinger equations in fractional order Sobolev spaces, Rev. Math. Phys., 9 (1997), 397-410, doi:10.1142/S0129055X97000154.

[19] K. NAKANISHI, Asymptotically-free solutions for the short-range nonlinear Schrödinger equation, SIAM J.Math.Anal., 32 (2001), 1265-1271, doi:10.1137/S0036141000369083.

[20] K. NAKANISHI AND T. OzAWA, Remarks on scattering for nonlinear Schrödinger equations, NODEA Nonlinear Differential Equations Appl., 9 (2002), 45-68, doi:10.1007/s00030-002-8118-9.

[21] T. OZAWA AND K. YAMAUCHI, Remarks on analytic smoothing effect for the Schrödinger equation, Math. Z., 261 (2009), 511-524, doi:10.1007/s00209-008-0334-5.

[22] T. Ozawa AND K. Yamauchi, Analytic smoothing effect for global solutions to nonlinear Schrödinger equation, J. Math. Anal Appl., 364 (2010), 492-497, doi:10.1016/j.jmaa.2009.09.033.

[23] T. OZAWA, K. YAMAUCHI AND Y. YAMAZAKI, Analytic smoothing effect for solutions to Schrödinger equations with nonlinearity of integral type Osaka Math. J., 42 (2005), 737-750.

[24] L. Robbiano And C. ZUILY, Microlocal analytic smoothing effect for the Schrödinger wquation, Duke Math. J., 100 (1999), 93-129.

[25] L. RobBiano AND C. Zuily, Effect régularisant microlocal analytique pour l'equation de Schrödinger : le cas données oscillantes, Comm. Partial Deifferential Equations, 25 (2000), 18911906.

[26] R.S. STRICHARTZ, Restrictions of Fourier transforms to quadratic surfaces and decay of solutions of wave equations, Duke. Math. J., 44 (1977), 705-714, doi:10.1215/S0012-7094-77-04430-1.

[27] J.C.H Simon AND E. TAFLIN, Wave operators and analytic solutions of nonlinear Klein-Gordon equations and of nonlinear Schrödinger equations, Commun. Math. Phys., 99 (1985), 541-562, doi:10.1007/BF01215909.

[28] C. Sulem And P.-L. Sulem, The nonlinear Schrödinger equation. Self-focusing and wave collapse, Appl. Math. Sci., 139, Springer 1999.

[29] H. TAKUWA, Analytic smoothing effects for a class of dispersive equations, Tsukuba J. Math., 28 (2004), 1-34.

[30] K. YaJima, Existence of solutions for Schrödinger evolution equations, Commun. Math.Phys., 110 (1987), 415-426, doi:10.1007/BF01212420. 